\title{
The dollar-euro exchange rate and macroeconomic fundamentals: a time-varying coefficient approach
}

\author{
Joscha Beckmann • Ansgar Belke • Michael Kühl
}

Published online: 17 November 2010

(C) The Author(s) 2010. This article is published with open access at Springerlink.com

\begin{abstract}
This paper investigates the temporal stability of the relationship between the Deutschmark/US dollar exchange rate and macroeconomic fundamentals. We use monthly data from 1975:01 to 2007:12. Applying a novel time-varying coefficient estimation approach, we come up with some interesting properties of our empirical model. Firstly, there is no stable long-run equilibrium relationship among fundamentals and exchange rates, since the breakdown of Bretton Woods. Secondly, there are no recurring regimes, i.e. across different regimes, either the coefficient values for the same fundamentals differ or the significance differs. Thirdly, there is no regime into which no fundamentals enter. Fourthly, the deviations resulting from the stepwise cointegrating relationship act as a significant error-correction mechanism. In other words, we are able to show that fundamentals play an important role in determining the exchange rate, but their impact differs significantly across different subperiods.
\end{abstract}

Keywords Structural exchange rate models - Cointegration - Structural breaks · Switching regression · Time-varying coefficient approach

J. Beckmann · A. Belke (ه)

Department of Economics, University of Duisburg-Essen, 45117 Essen, Germany

e-mail: ansgar.belke@uni-due.de

J. Beckmann

e-mail: joscha.beckmann@uni-due.de

A. Belke

Deutsches Institut für Wirtschaftsforschung (DIW), Berlin, Germany

A. Belke

Institute for the Study of Labor (IZA) Bonn, Bonn, Germany

M. Kühl

Department of Economics, University of Göttingen, 37073 Göttingen, Germany

e-mail: michael.kuehl@wiwi.uni-goettingen.de 
JEL Classification $\mathrm{E} 44 \cdot \mathrm{F} 31 \cdot \mathrm{G} 12$

\section{Introduction}

Disentangling the main drivers of exchange rates is still one of the most controversial research areas in economics. After the first generation models of exchange rate determination, which see the exchange rate as the relative price of domestic and foreign monies (Dornbusch 1976a, b; Frenkel 1976; Kouri 1976; Mussa 1976) were brought to the data, it became clear that exchange rate models can only partly be used to explain past exchange rates with the help of fundamentals, and that they perform poorly in forecasting, in particular (Meese and Rogoff 1983, 1988). The results of the seminal study by Meese and Rogoff (1983) still represent the benchmark: exchange rate forecasts by structural models can hardly outperform naïve random walk forecasts (Rogoff 2009).

Since then, many contributions have tried to refute their results. Sticking to the implicit assumption that exchange rates and fundamentals are cointegrated, and implementing exogenous parameter restrictions, a couple of authors find predictability in the long run for a similar period, as in Meese and Rogoff (Mark 1995; Chinn and Meese 1995). ${ }^{1}$ However, extending the estimation period yields mostly contrary findings (Kilian 1999; Abhyankar et al. 2005). A critical point is the implicit assumption of cointegration, which leads to biased conclusions if a stable long-run relation does not exist (Berkowitz and Giorgianni 2001).

While the empirical models of the late 1980s mostly neglected the potential existence of a long-run relationship between the fundamentals and the exchange rate, structural models were applied at the beginning of the 1990s which tested explicitly for a long-run relationship among exchange rates and fundamentals. These kinds of empirical model, which are based upon cointegration relationships, can indeed improve the evidence in favour of predictability in the long run when periods up to the end of the 1990s are covered (MacDonald and Taylor 1993, 1994). ${ }^{2}$ However, any extension of the sample period typically yields a breakdown in cointegration relationships (Groen 1999). Surprisingly, little attention is directed to an examination of the link between exchange rates and fundamentals with respect to structural changes in cases where cointegration does not hold.

Stock and Watson (1996) show that univariate and bivariate macroeconomic time series are subject to substantial instabilities which result in poor forecasting performance. Different market surveys suggest that various fundamentals are important during different periods (Cheung and Chinn 2001; Gehrig and Menkhoff 2006). Bacchetta and Wincoop (2009) argue that large and frequent variations in the relationship between the exchange rate and macro fundamentals naturally develop when structural parameters in the economy are unknown and subject to changes. As

\footnotetext{
${ }^{1}$ Mark (1995) is the first author who focuses on more than one exchange rates simultaneously. He includes the Canadian dollar, the Deutschmark, the Japanese yen and the Swiss franc expressed in US dollar. Chinn and Meese (1995) do include the pound sterling in US dollars as well as the US dollar and the Deutschmark in Japanese yen but not the Swiss franc.

${ }^{2}$ MacDonald and Taylor (1994) investigate the pound sterling-US dollar exchange rate.
} 
a consequence, market participants can give "excessive" weight to some (macroeconomic) fundamentals during specific periods, i.e. to so-called "scapegoats" (Bacchetta and van Wincoop 2004). Parameter instabilities then arise when the empirical realisation of such a scapegoat changes.

A similar explanation of parameter instabilities can be obtained from the imperfect knowledge approach (e.g. Goldberg and Frydman 1996b, 2007). This approach is based on the view that market participants do not know the exact model but use fundamentals for forecasting exchange rates in a way consistent with the assumed theory. Accordingly, the link between fundamentals and the exchange rate changes when the market participants revise their beliefs in the underlying model. Hence, it is reasonable to assume that a strong and significant relationship between exchange rates and fundamentals exists during some subperiods and that its nature tends to change considerably over time.

Goldberg and Frydman (1996a, b, 2001) report evidence that fundamentals do matter in a way which is not entirely consistent with the monetary model during some subperiods of floating while such evidence cannot be found during other periods. ${ }^{3}$ Thus, the instability of the monetary model in the data-generating process might serve as an explanation for the findings of Cheung et al. (2005). The latter suggest that model specifications which work well in one period do not necessarily work well in another period. ${ }^{4}$ From this point of view, a fundamental value of the exchange rate exists in the sense that a part of the exchange rate movements is driven by fundamentals.

In the recent past, models capable of taking different regimes into account have been applied to the monetary approach. ${ }^{5}$ For instance, Sarno et al. (2004) use a Markov regime-switching model in order to investigate the response of exchange rates to deviations from fundamental values in different regimes. Sarno and Valente (2009) demonstrate that exchange rate models that optimally use the information in the fundamentals often change, which in turn implies frequent shifts in the coefficients. What is more, de Grauwe and Vansteenkiste (2007) investigate particularly the adjustment of the nominal exchange with respect to changes in the fundamentals under different inflation regimes. Taylor and Peel (2000), Taylor et al. (2001) and Kilian and Taylor (2003) make use of models that allow for a smooth transition between two states, supporting the hypothesis that real exchange rate adjustment towards equilibrium paths are nonlinear. To be more specific, fundamentals become important if the deviation from an equilibrium rate is large.

\footnotetext{
3 The inability to find such evidence in other subperiods, such as the transition periods, does not mean that fundamentals do not matter. Rather, this may be due to small sample sizes or specification error. Also, even in the subperiods for which fundamentals are found to matter, the results are not entirely consistent with the monetary models.

4 See also Bacchetta and Wincoop (2009). Parameter instability, i.e. an unstable relationship between exchange rates and macro fundamentals, is confirmed by formal econometric evidence delivered by Rossi (2006).

5 For an analogous application to inflation and unemployment in the context of different political regimes see Belke (2000). He interprets the significance of the error-correction parameter after regime-dependent structural breaks in the long-run cointegrating relationship have been taken into account as empirical evidence of hysteresis.
} 
Frömmel et al. (2005a, b) test directly for the significance of different regimes in the exchange rate determination equation of the real interest rate differential model. However, since the authors specify their model in first differences, they do not investigate a long-run relationship in a strict sense. ${ }^{6}$ Joining Goldberg and Frydman (1996a, b, 2001), the coefficients in the exchange rate determination process itself are allowed to change within their framework. All other contributions focus on deviations of the exchange rate from a fundamental value which assumes cointegration with implied restrictions without modelling the long-run structure separately.

Both of the above-mentioned regime-switching approaches, however, have in common that they only allow for a fixed number of perseverative, i.e. regularly recurring, regimes. In early works, Schinasi and Swamy (1989) and Wolff (1987) applied a time-varying coefficient model (TVP) to monetary models. They were able to show that their models displayed rather better forecasting properties than fixed coefficient models. Hence, the consideration of time-varying coefficients appears to be a worthwhile next step towards a valid empirical model of the exchange rate.

Taking these considerations as a starting point, we address several research questions by using a general exchange rate determination model which is based upon the monetary approach and nests a range of variants of the latter. Our working hypothesis is that a relationship between the exchange rate and fundamentals continuously holds, but that its composition varies considerably over time. To test our hypotheses we proceed as follows: firstly, we check whether the long-run equilibrium relationship among some fundamentals and the US dollar exchange rate vis-à-vis the Deutschmark/euro since the breakdown of Bretton Woods I has been subject to structural changes. Secondly, we test whether the estimated relationships represent cointegrating relations. The latter is the case if the hypothesis of non stationarity of the error term resulting from the stepwise relationship can be rejected. As regards our third hypothesis, we check empirically whether fundamentals matter for each regime identified by us. Fourthly, we then test whether the regimes are not perseverative, which would imply that the empirical realisation of the estimated coefficients for specific fundamentals and/or their significance differs across different regimes. Fifthly, we focus on a test of rational expectations in the tradition of Goldberg (2000). Finally, we test whether the exchange rate adjusts to disequilibria and investigate whether the adjustment speed tends to be stable.

The remainder of this paper is organized as follows. Section 2 gives a short overview of the array of fundamental models we consider later on, and motivates coefficient instability from a theoretical perspective. In Sect. 3 we describe our econometric methodology and in Sect. 4 present the empirical results. We start with the estimation of a multiple structural change model, as developed by Bai and Perron $(1998,2003)$, which we apply to the reduced form of structural exchange rate models. As a next step, we make use of the estimated breakpoints to generate indicator functions, and, based on these, we estimate the structural model in order to obtain estimates for the different regimes. To this purpose, we apply the fully modified OLS estimator by Phillips and Hansen (1990), which is generally claimed

\footnotetext{
${ }^{6}$ In order to obtain a long-run perspective, Frömmel et al. (2005a, b) make use of annual changes constructed from a monthly data set.
} 
to be able to deal with nonstationary variables as regressors and regressands. Finally, we construct an error-correction term from the estimated relationships and regress the change of the exchange rate on this error-correction term, in order to investigate whether the exchange rate adjusts to deviations from a fundamental equilibrium relationship. Section 5 concludes.

\section{Monetary models of the exchange rate}

\subsection{Theories}

After the breakdown of Bretton Woods I, exchange rate models were developed which see exchange rates as asset prices (Dornbusch 1976a; Frenkel 1976; Kouri 1976). All models of this kind have in common that they rely on a stable money demand function of the form

$$
\frac{M}{P}=L\left(Y^{r}, i\right)
$$

with $M$ representing the money supply, $P$ the price level and $L$ the money demand depending on real income $(Y)$ and interest rates $(i)$. A basic assumption of the standard monetary model is that the purchasing power parity (PPP) holds. In the loglinearized form, the exchange rate can be expressed as the difference in price levels which is equal to the difference between domestic and foreign money supply less real money demand based on money market equations, so that the exchange rate is determined as follows:

$$
\begin{aligned}
s & =\alpha+\left(\beta_{1} m-\beta_{2} y+\beta_{3} i\right)-\left(\beta_{1}^{f} m^{f}-\beta_{2}^{f} y^{f}+\beta_{3}^{f} i^{f}\right) \\
& =\alpha+\beta_{1} m-\beta_{1}^{f} m^{f}-\beta_{2} y+\beta_{2}^{f} y^{f}+\beta_{3} i-\beta_{3}^{f} i^{f}
\end{aligned}
$$

In the literature, this model is widely known as the Frenkel and Bilson (FB) model. $^{7}$ A rise of the exchange rate $s$ corresponds to depreciation of the domestic currency. In the original monetary model $\alpha$ is zero and $\beta_{1}=\beta_{1}^{f}=1$. due to the structure of the money demand function. Equation 2 can be rewritten under the restriction that the (semi-) elasticities of the interest rates are equal. This yields:

$$
s=\alpha+\beta_{1} m-\beta_{1}^{f} m^{f}-\beta_{2} y+\beta_{2}^{f} y^{f}+\beta_{3}\left(i-i^{f}\right) .
$$

If the uncovered interest rate parity (UIP) holds, $\left(i-i^{f}\right)$ can be replaced by the expected change in the exchange rate $\left(E_{t}\left(s_{t+1}\right)-s_{t}\right)$. With an expectationgenerating mechanism based upon PPP, the differences in interest rates can then be replaced by the differences in expected rates of inflation. ${ }^{8}$ Since it is known that the exchange rate often deviates from the PPP the adjustment towards the PPP value can be taken into account in addition to the expectations concerning the expected

\footnotetext{
7 The terms $\beta$ are elasticities and $\alpha$ is a constant term. The variables $m$ and $y$ are the logarithms of money supply and real income. The interest rates are expressed as percentage.

${ }^{8}$ This expression is equivalent to a money demand function in which the expected rates of inflation enter as opportunity costs.
} 
rates of inflation $E_{t}\left(s_{t+1}-s_{t}\right)=-\phi\left(s_{t}-\bar{s}\right)+\pi_{t}-\pi_{t}^{f} .{ }^{9}$ The real interest rate model (RID) by Frankel (1979) arises if the expectation formation process is combined with the UIP and is solved for the expected change in the exchange rate (Eq. 4).

$$
s=\alpha+\beta_{1} m-\beta_{1}^{f} m^{f}-\beta_{2} y+\beta_{2}^{f} y^{f}-\beta_{3}\left(i_{t}-i_{t}^{f}\right)+\beta_{4}\left(\pi_{t}-\pi_{t}^{f}\right) .
$$

The negative sign of the interest rate differential implies that an increase in the differential is associated with an appreciation of the domestic currency. With the help of Eq. 4 a similar process can be explained as in the overshooting case of Dornbusch (1976a). In Dornbusch (1976a) the exchange rate is negatively correlated with the interest rate differential but without feedback on inflation expectations, i.e. $\beta_{4}$ is zero. Equation 4 allows the exchange rate to deviate from PPP in the short run, i.e. it reacts negatively on interest rates, but still positively on inflation rate expectations.

A weakness of the traditional monetary model is that the real exchange rate is assumed to be constant in the long run. Since it is expected that the PPP holds for traded goods rather than for a mixture of traded and non-traded goods, as implicitly assumed when using the overall price index, the prices of traded goods can be taken into account (Dornbusch 1976b). If the overall price index, which is determined by the money market, consists of prices of both traded and non-traded goods, and if the PPP is only valid for traded goods, then the monetary approach yields an exchange rate determination equation in the form ${ }^{10}$ :

$$
s=\alpha+\beta_{1} m-\beta_{1}^{f} m^{f}-\beta_{2} y+\beta_{2}^{f} y^{f}-\beta_{3}\left(i_{t}-i_{t}^{f}\right)+\beta_{4}\left(\pi_{t}-\pi_{t}^{f}\right)+\beta_{6} \frac{P_{t}^{T}}{P_{t}^{N T}}-\beta_{6}^{f} \frac{P_{t}^{f T}}{P_{t}^{f N T}} .
$$

In the flex-price model, $\beta_{4}$ is equal to zero and the exchange rate reacts positively to the interest rate differential (Wolff 1987). The proportion of traded to non-traded goods mirrors the real exchange rate. A rise in the price of tradables relative to that of non-tradables causes the nominal exchange rate to increase because the domestic good is substituted by the foreign good. Such a rise might result from productivity differentials between countries as expressed by the Harrod-Balassa-Samuelson effect (Harrod 1939; Balassa 1964; Samuelson 1964). Wu and Hu (2009) recently emphasized the importance of the Harrod-Balassa-Samuelson effect when modelling deviations from purchasing power parity using an ESTAR model.

In order to take account of real shocks, Hooper and Morton (1982) implement changes of the equilibrium real exchange rate into the traditional monetary model (HM model). In addition to nominal impact factors, the real side of the economy was introduced by taking into consideration innovations in the current account. Hooper and Morton (1982) also use overall trade balances as an indicator of the risk premium which arises from government debt, an insufficient holding of international reserve, and foreign indebtedness. A fall in the net foreign asset position (in particular if it is negative) raises the risk premium and, hence, depreciates the

\footnotetext{
9 The parameter $\phi$ denotes the adjustment speed towards the equilibrium value $\bar{s}$. The parameter $\pi$ denotes the expected rate of inflation.

${ }^{10}$ The parameter $T$ denotes tradables and NT denotes non-tradables.
} 
domestic exchange rate. Hence, the risk premium reacts sensitively to a worsening negative net foreign asset position. Thus, Eq. 4 can be extended by the cumulated trade balances as a proxy for the overall trade balance (Eq. 6). ${ }^{11}$

$$
\begin{aligned}
s= & \alpha+\beta_{1} m-\beta_{1}^{f} m^{f}-\beta_{2} y+\beta_{2}^{f} y^{f}-\beta_{3}\left(i_{t}-i_{t}^{f}\right)+\beta_{4}\left(\pi_{t}-\pi_{t}^{f}\right)-\beta_{5} C T B_{t} \\
& +\beta_{5}^{f} C T B^{f} .
\end{aligned}
$$

In applied monetary models, Eq. 2 is typically estimated based by means of a reduced form for which it is assumed that the elasticities of an economic variable are identical in both countries. Hence, the restrictions $\beta_{1}=\beta_{1}^{f}, \beta_{2}=\beta_{2}^{f}$ and $\beta_{3}=$ $\beta_{3}^{f}$ apply (Meese and Rogoff 1983). However, any analysis in which the coefficients are restricted to be equal for each variable typically tends to result in biased coefficients (Haynes and Stone 1981). If the structure of the economy is not known a priori, restricted coefficients do not help in explaining the exchange rate. While the traditional monetary model assumes that domestic and foreign assets are perfect substitutes, the assumption is relaxed by highlighting the role of risk, as Hooper and Morton point out (1982). One model which explicitly takes risk premia into account is the portfolio balance model (Branson 1977). If a risk premium gains in importance, it is preferable to use this portfolio balance approach. In such a case the symmetry restriction regarding interest rates is relaxed because the domestic and foreign bonds are not perfect substitutes. Using arguments stemming from the imperfect knowledge approach, Goldberg (2000) has shown that a rejection of the symmetry restriction relating to the interest rate differential is either linked to imperfect capital mobility or provides evidence in favour of the imperfect knowledge approach over rational expectations. Although a precise distinction between both explanations is not empirically possible, he concludes that the absence of capital controls in most countries points towards the inadequacy of the rational expectation hypothesis (Goldberg 2000).

In the following, we employ a hybrid model which picks up effects that can be found in both monetary and portfolio models (Frankel 1983). As a consequence, we remove the restrictions of parameter equality in the interest rate differential and the inflation rate differential in our Eqs. 4 and 6. Thus, we start our analysis in as unrestrictive as possible manner, bearing in mind the dynamics stemming from both the portfolio balance approach and the monetary approach.

\subsection{Long-run analysis with time-varying coefficients}

Wolff (1987) gives three reasons why a time-varying coefficient model should be superior to fixed-coefficient models. First of all, the money demand function is subject to instabilities, which cause the coefficients in the exchange rate determination equation of a reduced model to change (Leventakis 1987). Another reason is given by the famous Lucas critique: coefficients change if an anticipated change in the policy regime occurs. The third argument is related to the long-run real exchange rate. The monetary model assumes that purchasing power parity holds

\footnotetext{
11 Since data on the current account are not available at a monthly frequency, it appears adequate to proxy the current account by the trade balance.
} 
in the long run, from which follows that the long-run real exchange rate is stable. Innovations in the real exchange rate from the real side of the economy can lead to changes in the coefficients. Because we explicitly account for changes in the real exchange rate, the latter issue deserves less attention in our analysis with respect to the choice of estimation technique.

A reason for choosing time-varying coefficient models can also be derived from different theories. In inter-temporal new open economy macroeconomic (NOEM) models (Obstfeld and Rogoff 1995), money demand does not depend on income, but on real consumption. If we proxy real consumption by real income, a change in the average rate of consumption results in a change in the elasticity of income in the exchange rate equation. Thus, if consumption shares do vary, which is, for instance, true for the US, the exchange rate determination equation thus also becomes time varying.

As argued by Wilson (1979), an anticipated policy change, i.e. an expansionary monetary policy, can generate a kind of dynamics which is different from those stemming from unanticipated changes. Following Wilson (1979), the overshooting dynamics is slightly different from those of Dornbusch (1976a). A very important result is that an appreciation period of the domestic currency coincides with the increase in money supply, while in the Dornbusch model a boost in money supply coincides with a depreciation of the former. If anticipated and unanticipated shocks alternate, fixed coefficient models are inadequate because they cannot capture both effects simultaneously. This argument is particularly relevant if the frequency of observation is a monthly one. In such a case, these effects will influence the longrun relationship and not enter the short-term dynamic.

Furthermore, the consistent expectations theory developed by Goldberg and Frydman (1996a, 2001, 2007), which is based upon the imperfect knowledge approach, offers a broad theoretical framework that is able to explain why some fundamentals might matter during some time periods, but not during others. The authors argue that combinations of different fundamentals need not be systematically similar, as market participants intermittently revise their views as to how fundamentals influence the exchange rate. They show that macroeconomic fundamentals can drive exchange rate swings. Such swings can therefore be explained with the help of the basic relationships in a monetary model with either flexible or sticky prices, if the assumption of rational expectations is replaced with an Imperfect Knowledge representation of forecasting behaviour (Goldberg and Frydman 2007). Within this framework, market participants only have a rough knowledge concerning the link between exchange rate and fundamentals, suggesting that they are only able to determine the sign of the fundamentals with respect to their influence on the exchange rate. The authors conclude that it is not reasonable to base an empirical analysis on a fully predetermined model, as it is not possible to pre-specify either the fundamentals or the way these fundamentals influence the exchange rate.

According to the results gained by Sarno et al. (2004), and de Grauwe and Vansteenkiste (2007), the adjustment of exchange rates towards the long-run equilibrium relationship also does not appear to be time-invariant. Consequently, we expect that adjustment differs from period to period, at least over a long span of 
data. An adjustment towards the long-run equilibrium relationship can occur because the exchange rate predominantly reacts to the fundamentals, or because, conversely, the fundamentals react to changes in exchange rates. In the latter case, it is possible that the exchange rate does not adjust in subperiods. The changing of an adjustment coefficient can be due to the revision of beliefs concerning the importance of macroeconomic factors. An increase should coincide with a homogeneity of beliefs regarding the fundamental model. If no fundamental factor matters, the adjustment coefficient will be zero in the corresponding period. Consequently, the adjustment coefficient has the potential to differ between subperiods.

Siklos and Granger (1997) have developed a framework which appears to be well suited to analyzing these issues in the necessary detail. They point out that a cointegration relationship can be subject to structural changes, and argue that the common stochastic trends are only present in specific periods. In this respect, they introduce the concept of regime-sensitive cointegration, or "switch on-switch off" cointegration. In addition to a time-varying cointegration vector, their framework also allows the causality between the variables to change during the period of observation. This means that the dimension of the vector which contains the adjustment coefficients can be reduced during subperiods.

In our long-run relationship analysis we are thus potentially simultaneously confronted with switch on and off cointegration, a changing cointegration vector and the adjustment process. The main difficulty inherent in our estimations, then, is coping with potential overlaps of these phenomena. Hence, our approach takes account of different regimes. It is able to distinguish between cases in which the cointegration relationship is switched on and those in which different adjustments are present. In this paper, our working hypothesis is that cointegration is continuously present over the whole period of observation, while only the composition of the cointegration vector changes. An empirical rejection of this hypothesis, which can be observed if either no fundamental factor enters the cointegration relationship or the exchange rate does not adjust to disequilibria from the estimated long-run relationship, is compatible with the results of Goldberg and Frydman (1996a, 2001, 2007) who inspired our approach quite heavily. Our approach in principle delivers the same empirical pattern as their setting: different fundamentals matter in different ways during different time periods and the resulting regimes are not perseverative. Nevertheless, some differences remain. Whereas our aim is to show that cointegration is continuously present, with only the composition of the vector changing, the study of Goldberg and Frydman (1996a, b, 2001) in principle allows for the possibility that cointegration does not exist during subperiods. For example, the results of Goldberg and Frydman's (1996b) structural change analysis imply a couple of subperiods that are too small to estimate a relationship between exchange rates and fundamentals. However, this does not necessarily imply that fundamentals do not matter during these subperiods.

For a multivariate case we consider the term

$$
Y_{t}=\mu_{t}+\boldsymbol{\beta}_{t} \mathbf{X}_{t}+\varepsilon_{t}
$$


with

$$
\mathbf{X}_{t}=\left[X_{t}^{1}, \ldots, X_{t}^{k}\right] \text { for } n=1, \ldots, K,
$$

where $K$ represents the maximum number of explanatory variables. ${ }^{12}$ The matrix $\mathbf{X}_{t}$ has the dimension $(K \times 1)$ and $\boldsymbol{\beta}_{t}$ the dimension $(1 \times K)$. In our empirical analysis, we put the following composite model under closer scrutiny:

$$
Y_{t}=s_{t}, \mathbf{X}_{t}=\left(m y i \pi m^{f} y^{f} i^{f} \pi^{f} \frac{p^{T}}{p^{N T}} \frac{p^{f T}}{p^{f N T}} \Delta C T B \Delta C T B^{f}\right)^{\prime} .
$$

This model nests all models described in Sect. 2.1. Consequently, we can use this equation to assess the empirical validity of the presented models in Sect. 4 by applying Wald tests.

\section{Modeling structural changes and estimating cointegrating relations-methodological issues}

\subsection{Testing for multiple structural changes}

In general, two frameworks for tests for structural change can be distinguished. The first one consists of generalized fluctuation tests in which a model is fitted to the data and an empirical process is derived that captures these fluctuations either in the residuals or in coefficient estimates. If the generated process exceeds the boundaries of the limiting process, which can be derived from the functional central limiting theorem, the null hypothesis of parameter constancy has to be rejected. This implies that a structural change occurs at the corresponding point in time (Zeileis et al. 2003).

The classical and the OLS based CUSUM test and the fluctuation test of Nyblom (1989) are well-known examples of such kind of methods. These structural change tests are predominantly designed for stationary variables. In the case of a cointegration analysis an eigenvalue fluctuation test developed by Hansen and Johansen (1999) which heavily relies upon Nyblom can be applied. While these procedures have the advantage of not assuming a particular pattern of deviation from the null hypothesis they can either only identify a single break or show general instability.

The second framework to test for structural changes is to compare the OLS residuals from regressions for different subsamples. This can be done, for example, by applying the $F$-statistics or the Chow test. In this paper, we exclusively adopt an extension of the latter case developed by Bai and Perron (1998, 2003). Their basic idea is to choose breakpoints such that the sum of squared residuals for all observations is minimized.

As a starting point, consider a multiple linear regression with $m$ breakpoints and $m+1$ regimes

$$
y_{t}=x_{t}^{\prime} \mathbf{\kappa}+z_{t}^{\prime} \boldsymbol{\delta}_{j}+u_{t},\left(t=T_{j-1}+1, \ldots, T_{j}\right),
$$

\footnotetext{
${ }^{12}$ The term $\mu_{t}$ denotes a regime-dependent constant term. The variable $\varepsilon_{t}$ represents an error term.
} 
for $j=1, \ldots, m+1$ with the convention that $T_{0}=0$ and $T_{m+1}=T$. The term $y_{t}$ denotes the dependent variable, $x_{t}^{\prime}$ and $z_{t}^{\prime}$ denominate the regressors and $\boldsymbol{\kappa}$ and $\boldsymbol{\delta}$ are the coefficient vectors. Note that only $\boldsymbol{\delta}$ varies over time while $\boldsymbol{\kappa}$ is constant.

With a sample of $T$ the first step is to calculate the corresponding values for all possible $T(T+1) / 2$ segments. ${ }^{13}$ The estimated breakpoints $T_{1}, \ldots, T_{m}$ by definition represent the linear combination of these segments which achieve a minimum of the sum of squared residuals (Bai and Perron 2003). Formally:

$$
\left(\hat{T}_{1}, \ldots, \hat{T}_{m}\right)=\arg \min _{T_{1}, \ldots, T_{m}} S_{T}\left(T_{1}, \ldots, T_{m}\right) .
$$

Bai and Perron (2003) develop a dynamic programming algorithm which compares all possible combinations of the segments. Their methodology allows testing for multiple structural breaks under different conditions. ${ }^{14}$ Within our framework, the location of the breakpoints is also obtained by calculating the sum of squared residuals. To select the dimension of the model we apply the Bayesian Information Criterium (BIC) which according to Bai and Perron (2003) works well in most cases when breaks are present. After calculating the tests for all possible breakpoints the sequence $\left(\hat{T}_{1}, \ldots, \hat{T}_{m}\right)$ is selected as the configuration at which the BIC achieves its minimum. Carrion-i-Silvestre and Sanó (2006) show that this approach yields a consistent estimate of the break fraction. The breakpoints obtained in this fashion are a local minimum of the sum of squared residuals given the number of breakpoints but not necessary a global minimum.

It is important to note that the procedure of Bai and Perron has originally been developed for the case of stationary variables $(\mathrm{I}(0))$. Nevertheless, it can as well be applied to nonstationary variables which are integrated of order one (I(1)). For instance, Siklos and Granger (1997) use this methodology to identify structural breaks in the interest parity equation between the United States and Canada in the context of regime-sensitive cointegration. In addition, Zumaquero and Urrea (2002) point out that the break estimator is consistent also in the nonstationary case. Using disaggregated price indexes for seven countries, they test for structural breaks in the coefficients of cointegrating relations which represent absolute and relative purchasing power parity. They also examine instabilities in the adjustment behaviour of price ratios and exchange rates. Finally, Kejriwal and Perron (2008) demonstrate that the results of Bai and Perron (1998) in general continue to hold even with $\mathrm{I}(0)$ and $\mathrm{I}(1)$ variables in the regression. ${ }^{15}$ This is also true if one allows

\footnotetext{
13 Bai and Perron (1998) note that for practical purposes less than $T(T+1)$ segments are permissible, for example if a minimum distance between each break is imposed. In the framework of this paper, breaks are allowed to occur every 12 months.

14 One possibility is to test the null of no change against the hypothesis of a fixed number of breaks $m=k$ using $F$-tests based on the sum of squared residuals under both hypotheses. For an unknown number of breaks, one way is to allow a maximum number of breaks. In this case one can apply the so called double maximum test. The number of breakpoints is then selected by comparing the $F$-values described above for the different numbers of breakpoints and select the configuration with the highest $F$-value respectively the minimum of the sum of the squared residuals. Another possibility is to test sequentially for an additional break using the " $l$ vs. $l+1$ " break tests. For details see Bai and Perron (1998, 2003).

15 This is only true if, as in our case, the intercept is allowed to change across segments.
} 
for endogenous I(1) regressors. ${ }^{16}$ The use of information criteria as the BIC is also correct in both cases.

To check our results for robustness, we also apply the CUSUM test combined with Andrews and Ploberger (1996) in a similar way as Goldberg and Frydman (2001) to detect possible breakpoints. However, with no considerable differences arising from the results, we proceed using the breakpoints obtained by the Bai and Perron methodology.

\subsection{Estimating cointegrating relations with single equations}

After identifying the breakpoints we now turn to the issue of correct estimation. As Bai and Perron's methodology is designed for single equations, we cannot consider multivariate system estimators as proposed by Johansen (1988) or Stock and Watson (1988). Besides the traditional approach of Engle and Granger (1987), several modified single estimators have been developed. Examples are the fully modified estimator by Phillips and Hansen (1990) and the approach of Engle and Yoo (1991). ${ }^{17}$ Even in the case of a multi-dimensional cointegration space, single equation approaches can be used to achieve asymptotically efficient estimates of single cointegrating relationships.

For our purposes, the fully modified (FM) estimator is the most suitable method. In contrast to traditional single equation formulas it considers endogenous regressors (Phillips 1991). Phillips and Hansen (1990) show that the FM-OLS estimator is hyperconsistent for a unit root in single equations autoregression. Phillips (1995) proves that this procedure is reliable in the case of full rank or cointegrated I(1) regressors ${ }^{18}$ as well as with $\mathrm{I}(0)$ regressors. Hargreaves (1994) runs a Monte Carlo simulation and points out that single estimators, in general, are robust if more than one cointegrating relation exists, with the FM-OLS estimator doing best. He concludes that the FM-OLS estimator should be preferred, even in advance of multivariate methods, if one wants to examine one cointegrating vector and is unsure about the cointegrating dimensionality. This is of particular interest for this paper, as we are primarily interested in the long-run relationship between exchange rates and fundamentals, and do not wish to pay too much attention to other cointegrating relationships which might arise between the reported fundamentals. Caporale and Pittis (1999) claim that the FM-OLS estimator and the Johansen estimator perform best in finite samples. ${ }^{19}$ Goldberg and Frydman (2007) use the systems approach developed by Phillips (1991), which is similar to the FM-OLS method for testing for cointegration between the exchange rate and fundamentals in a regime-sensitive framework.

\footnotetext{
${ }^{16}$ For the case without unit roots, Perron and Yamamoto (2008) show that the estimation of the break dates via OLS is preferable to an IV procedure in the presence of endogenous regressors.

${ }^{17}$ For a review of the different estimation methods of estimating cointegrating relationships see Hargreaves (1994), Phillips and Loretan (1991) and Caporale and Pittis (1999).

${ }^{18}$ Note that the direction of cointegration does not need to be known. Regressors containing a deterministic trend are also allowed.

${ }^{19}$ Furthermore, also Phillips and Hansen (1990), Hargreaves (1994) and Cappuccio and Lubian (2001) report good finite sample properties of the FM-OLS estimator.
} 
The root idea of this concept is to estimate cointegrating relations directly by correcting traditional OLS with regard to endogeneity and serial correlation (Phillips 1995). Let $\mathbf{z}_{t}$ denominate an $n$-vector where $y_{t}$ denotes an $r$-dimensional I(1) process while $\mathbf{X}_{t}$ is an $(n-r)=\left((n-r)_{1}+(n-r)_{2}\right.$-dimensional vector of cointegrated or possibly stationary regressors and $\mathbf{u}_{t}$ represents an n-vector stationary time series. Both vectors can be partitioned as follows:

$$
\mathbf{z}_{t}=\left[\begin{array}{c}
y_{t} \\
x_{1 t} \\
x_{2 t}
\end{array}\right], \mathbf{u}_{t}=\left[\begin{array}{l}
u_{1 t} \\
u_{2 t} \\
u_{3 t}
\end{array}\right] .
$$

The data generating process of $y_{t}$ is represented by the following cointegrated relation

$$
y_{t}=\boldsymbol{\beta} \mathbf{x}_{1 t}+u_{1 t} .
$$

The vectors of the regressors are specified as follows

$$
\begin{gathered}
\Delta \mathbf{x}_{1 t}=u_{2 t}, \\
\mathbf{x}_{2 t}=u_{3 t} .
\end{gathered}
$$

The estimator corrections can be applied without pre-testing the regressors for unit roots as both corrections can be conducted by treating all components of $\mathbf{x}_{t}$ as nonstationary. For the nonstationary components, this transformation reduces asymptotically to the ideal correction while the differenced stationary components vanish asymptotically. Such a correction does not have any effect on the subvectors of $\mathbf{x}_{t}$ where serial correlation or endogeneity are not present. ${ }^{20} \mathrm{~A}$ further advantage is that we do not have to account for cointegration between the $\mathbf{x}_{1 t}$ regressors within this methodology (Phillips 1995).

To imply the corrections, we first consider the long-run covariance matrix $\Omega$ which can be decomposed into a contemporaneous variance and the sums of autocovariances (Hargreaves 1994).

$$
\begin{gathered}
\Omega=E\left(u_{t} u_{t}^{\prime}\right)+\sum_{k=2}^{\infty} E\left(u_{0} u_{k}^{\prime}\right)+\sum_{k=2}^{\infty} E\left(u_{k} u_{0}^{\prime}\right) \\
\Omega=\sum+\lambda+\lambda^{\prime}
\end{gathered}
$$

We define $\Delta$ as

$$
\Delta=\sum+\lambda
$$

Estimation of these covariance parameters can be achieved by using the prewhitened kernel estimator suggested by Andrews and Monahan (1992). ${ }^{21}$ The endogeneity correction then has the form

\footnotetext{
${ }^{20}$ Without serial correlation or endogeneity the FM-OLS estimator is identical to the OLS estimator.

21 Other studies adopt the estimator of Newey and West (1987) which is robust to serial correlation and heteroskedasticity. For details see Cappuccio and Lubian (2001).
} 


$$
y_{t}^{*}=y_{t}-\hat{\Omega}_{0 x} \hat{\Omega}_{x x}^{-1} \Delta \mathbf{X}_{t} .
$$

The above correction is employed to account for endogeneities in the regressors $\mathrm{x}_{0 t}$ linked with any cointegration between $\mathrm{x}_{0 t}$ and $y_{t}$. The second correction takes into account the effects of serial covariances in the shocks $u_{t}$ and any serial covariance between $u_{0 t}$ and the history of $u_{1 t}$. The bias effect arises from the persistence of shocks due to the unit roots in $x_{1 t}$. The induced one-sided long-run covariance matrices carry these effects in an OLS regression (Phillips 1995). They can be defined as

$$
\hat{\Delta}_{0 x}=\hat{\Omega}_{00}-\hat{\Omega}_{0 x} \hat{\Omega}_{x x}^{-1} \hat{\Omega}_{x 0} .
$$

The correction is then given by

$$
\hat{\Delta}_{0 x}^{*}=\hat{\Delta}_{0 x}-\hat{\Omega}_{0 x} \hat{\Omega}_{x x}^{-1} \hat{\Delta}_{x x} .
$$

Combining both corrections the formula for the fully modified estimator is ${ }^{22}$

$$
\hat{\beta}^{*}=\left(Y^{*^{\prime}} X-T \widehat{\Delta}_{0 x}^{*}\right)\left(X^{\prime} X\right)^{-1} .
$$

\subsection{Regime shifts in cointegration models}

To apply the FM-OLS estimator in a model with structural changes we proceed in a similar way as Hansen (2003) does in the Johansen framework by allowing the coefficients to change their values at the breakpoints. ${ }^{23}$

We rewrite Eq. 22 with $\mu(t)$ as a constant

$$
y_{t}=\mu(t)+x_{t}^{\prime} \beta(t)+u_{t} .
$$

The piecewise constant time-varying coefficients are given by

$$
\begin{gathered}
\mu_{j}(t)=\mu_{0}+\mu_{1} 1_{1 t}+\cdots+\mu_{m} 1_{m t}, \\
\beta_{j}(t)=\beta_{1} 1_{1 t}+\cdots+\beta_{m} 1_{m t}
\end{gathered}
$$

where the indicator function for each subsample is defined as follows (Hansen 2003)

$$
1_{m t}=1\left(T_{j-1}+1<t<T_{j}\right) \mathbf{J} \quad \text { with } j=1, \ldots, m
$$

with the convention that $T_{0}=0$ and $T_{m}=T$. Defining dummies according to the indicator function ensures that we are able to obtain estimates for each period. In a similar way, the error correction representation can be rewritten by allowing for structural changes in the adjustment process.

$$
\Delta y_{t}=\zeta(t)+\alpha(t)\left(y_{t-1}-\mu(t-1)-\mathbf{x}_{t-1}^{\prime} \beta(t-1)\right)+e_{t}
$$

\footnotetext{
${ }^{22}$ The traditional OLS estimator is given by $\hat{\boldsymbol{\beta}}=Y^{\prime} X\left(X^{\prime} X\right)^{-1}$.

${ }^{23}$ We corroborated our results with a related approach introduced by Gregory and Hansen (1996). They model the changes in the intercept and the slope coefficients relative to the first subperiod as a benchmark, running from 0 to $T_{1}$. The base model is then written as $y_{t}=\mu_{1}+\mu(t)+\mathbf{x}_{t}^{\prime} \mathbf{k}_{1}+$ $\mathbf{x}_{t}^{\prime} \mathbf{k}(t)+z_{t}^{\prime} \boldsymbol{\delta}_{1}+z_{t}^{\prime} \boldsymbol{\delta}_{j}(t)+u_{t}$.
} 
$\zeta(t)$ in Eq. 27 is a constant and $e_{t}$ the residuals from the error correction model. The term $\alpha(t)$ represents the adjustment coefficient concerning deviations from the longrun equilibrium. Similarly to Eq. 25, a corresponding indicator function can be defined for $\alpha(t)$. The indicator function for $\zeta(t)$ is equivalently equal to Eq. 24 .

\section{Data and estimated models}

\subsection{Data}

Our sample contains monthly data running from January 1975 until December 2007. We use the aggregate M1 for money supply. Real income is proxied by the real production index. As suggested by Wolff (1987) the producer price index serves as a proxy for tradable goods while the basket of non-tradables is reflected by the consumer price index (CPI). Furthermore, we use the overall trade balance as an approximation of the current account. As seen in the Hooper-Morton model, the equilibrium flow determines the equilibrium stock. For the short-term interest rates we use money market rates with a maturity of 3 months. Exchange rates, money supply and real income are expressed in logarithms. All series are seasonally adjusted and are taken from International Financial Statistics of the International Monetary Fund.

In strong contrast to other studies investigating the euro exchange rate, we rely on the Deutschmark and the fundamentals of Germany before the introduction of the euro. The reason is that we are interested in market rates which could be contrasted by using weighted ECU-Data. In a sense, the Deutschmark has been a predecessor of the euro as it had a similar importance on the foreign exchange market. One reason was the big influence of the German Bundesbank (Fratianni and von Hagen 1990). We therefore use a time series which contains the German values until December 1998 and, from then on, the values of the euro area. Consequently, the Deutschmark/US dollar exchange rate is converted by the official Deutschmark/euro exchange rate in order to obtain a level adjustment. As a consequence, we also adjust the German fundamentals in levels to allow for a smooth transition to the euro area data. Since we deal with structural break models in the empirical section, we do not see any problems with our proceeding. The reason is that if a break due to data adjustment were important, the Bai-Perron test would signify a break around January 1999.

\subsection{Preliminary tests for unit roots and stationarity}

Although the FM-OLS estimator and the Bai-Perron methodology are basically able to handle a combination of $\mathrm{I}(0)$ and $\mathrm{I}(1)$ regressors, testing the data for unit roots is necessary as a first step. With the exchange rate being an $\mathrm{I}(1)$ variable, the concept of cointegration only makes sense if the fundamentals can also be treated as I(1) processes. By definition, a cointegrating relationship can only exist between variables which are integrated of the same order (Engle and Granger 1987). 
Table 1 Unit root tests

\begin{tabular}{|c|c|c|c|c|c|c|c|c|}
\hline \multirow[t]{3}{*}{ Variable } & \multicolumn{4}{|l|}{ Levels } & \multicolumn{4}{|c|}{ First differences } \\
\hline & \multirow{2}{*}{$\begin{array}{l}\text { PP } \\
\text { Test } \\
\text { statistic }^{\text {a }}\end{array}$} & \multicolumn{2}{|c|}{ DF-GLS } & \multirow{2}{*}{$\begin{array}{l}\text { KPSS } \\
\text { Test } \\
\text { statistic }^{c}\end{array}$} & \multirow{2}{*}{$\begin{array}{l}\text { PP } \\
\text { Test } \\
\text { statistic }^{\mathrm{a}}\end{array}$} & \multicolumn{2}{|c|}{ DF-GLS } & \multirow{2}{*}{$\begin{array}{l}\text { KPSS } \\
\text { Test } \\
\text { statistic }^{c}\end{array}$} \\
\hline & & Lags & $\begin{array}{l}\text { Test } \\
\text { statistic }^{b}\end{array}$ & & & Lags & $\begin{array}{l}\text { Test } \\
\text { statistic }^{b}\end{array}$ & \\
\hline$E U R / U S D$ & -1.317 & 2 & -0.437 & $2.690^{* *}$ & $-16.660 * *$ & 0 & -1.485 & 0.084 \\
\hline$m^{E M U}$ & -1.662 & 0 & -1.691 & $1.008 *$ & $-21.800^{*}$ & 0 & $-19.335^{*}$ & 0.123 \\
\hline$y^{E M U}$ & -3.36 & 15 & -2.693 & $0.182 * *$ & $-31.059^{*}$ & 0 & $-25.513^{*}$ & 0.049 \\
\hline$i_{s}^{E M U}$ & -1.97 & 0 & -1.154 & $1.840 * *$ & $-19.86 * *$ & 0 & $-17.069 *$ & 0.074 \\
\hline$\pi^{E M U}$ & -2.594 & 12 & -0.651 & $2.012^{* *}$ & $-17.32 * *$ & 0 & $-7.782 * *$ & 0.11 \\
\hline$\Delta C T B^{E M U}$ & $-4.048^{*}$ & 0 & $-4.643^{*}$ & $0.566^{*}$ & $-31.772^{*}$ & 0 & $-30.161 *$ & 0.062 \\
\hline$m^{U S}$ & -0.027 & 8 & -0.669 & $1.543^{*}$ & $-15.202 *$ & 16 & $-2.121 * *$ & $1.696^{*}$ \\
\hline$y^{U S}$ & -1.839 & 0 & -1.253 & $0.489 *$ & $-15.268^{*}$ & 0 & $-3.335^{*}$ & 0.083 \\
\hline$i_{s}^{U S}$ & -1.899 & 12 & -1.636 & $3.466^{*}$ & $-16.559 *$ & 0 & $-16.480^{*}$ & 0.456 \\
\hline$\pi^{U S}$ & -2.581 & 12 & -0.373 & $3.551^{*}$ & $-13.701^{*}$ & 0 & $-13.606^{*}$ & 0.178 \\
\hline$\Delta C T B^{U S}$ & -0.62 & 0 & -0.974 & $1.336^{*}$ & $-28.596^{*}$ & 0 & $-16.376^{*}$ & $0.628 * *$ \\
\hline
\end{tabular}

* and ** denote statistical significance at the levels of 10 and 5\%, respectively. For the PP test and the DF-GLS test the series contain a unit root under the null, whereas the KPSS test assumes stationarity under the null

${ }^{a}$ Critical values are taken from MacKinnon (1991): 5\% -2.86, 1\% -3.43

b Critical values are taken from Elliot et al. (1996): 5\% -1.95, 1\% -2.58. The number of lags is chosen using the modified AIC (MAIC) by $\mathrm{Ng}$ and Perron (2001). The maximum lag number is selected according to Schwert (1989) criterion

${ }^{c}$ Critical values are given by Kwiatkowski et al. (1992): 5\% 0.463, $1 \%$ 0.739. Autocovariances are weighted by Bartlett kernel. The variable $m$ denotes money supply, $y$ real income, $i_{s}$ short-term interest rates, $\pi$ inflation rate expectations and $\triangle C T B$ the change in the cumulated trade balance. EUR/USD is the euro price of one unit US dollar. Sample period: 1975:01-2007:12

Neither can a stationary variable force a nonstationary variable to adjust, nor is a stationary relationship between $\mathrm{I}(1)$ and $\mathrm{I}(2)$ variables possible. The distinction between the $\mathrm{I}(1)$ and $\mathrm{I}(2)$ variables is important in our context as there is much evidence in the literature that it is better to treat macroeconomic time series, like money supplies and exchange rates, as $\mathrm{I}(2)$ rather than $\mathrm{I}(1)$ processes. In those cases, a standard I(1) analysis might lead to biased conclusions (Juselius 2006). ${ }^{24}$

To test for unit roots, we apply the Phillips-Perron (PP), the KwiatkowskiPhilips-Schmidt-Shin (KPSS) and the GLS-based Dickey-Fuller (DF-GLS) tests. In the first instance, we test for stationarity in the levels. Differences are taken and tested again if a unit root remains, i.e. if the corresponding variables are integrated of order two. If both hypotheses are rejected we conclude that the variable is I(2). According to our results, most of our variables can be considered as being integrated of order one. The results of the tests are presented in Table 1.

\footnotetext{
$\overline{24}$ Frydman et al. (2010) account for this issue by using an I(2) framework to analyze long swings in the Deutschmark/US dollar exchange rate.
} 
Table 2 Dating of breakpoints in monetary models of the exchange rate

\begin{tabular}{lc}
\hline Year & Month \\
\hline 1977 & 07 \\
1981 & 09 \\
1985 & 03 \\
1988 & 10 \\
1991 & 02 \\
1993 & 12 \\
1999 & 03 \\
2004 & 11 \\
No. of breaks: 8 & 03
\end{tabular}

The reported breakpoints are obtained by applying the Bai and Perron $(1998,2003)$ methodology to the regression $Y_{t}=\mu(t)+\boldsymbol{\beta}(\mathbf{t}) \mathbf{X}_{t}+\varepsilon_{t}$ and the composite model described in Sect. 2. The variable $Y_{t}$ contains the euro-US dollar exchange rate and $\mathbf{X}_{t}$ is a $\mathbf{K} \times \mathbf{1}$ vector of $K$ fundamentals of each model. Sample period: 1975:01-2007:12

However, in a few cases, the evidence is mixed. For instance, our results for the cumulated overall trade balance suggest that this variable is integrated of order two. ${ }^{25}$ Therefore, we decide to work with first differences of the US and the euro area trade balance series. This can be done without changing the underlying economic theory. What is more, the KPSS test rejects the null hypothesis of stationarity of the change in the US money supply and the second difference of the trade balance of the euro area. However, since the other tests indicate I(1) properties of the respective series we treat them all as $\mathrm{I}(1)$.

\subsection{Empirical results}

\subsubsection{Assessing the stability of the long-run relationship}

We now derive the main hypotheses, to be tested in the following, from the arguments developed in Sect. 2. Our first hypothesis concerns the stability of a longrun exchange rate determination equation and runs as follows:

H1 There is no stable long-run relationship between the fundamentals and the EUR/USD exchange rate.

If the empirical application of the Bai-Perron test corroborates the existence of structural breaks, we cannot reject the validity of hypothesis $H 1$. We present the breakpoints identified by applying the Bai-Perron methodology in Table 2 . With an eye on the fact that we are able to identify eight breakpoints, we feel legitimized to state that breaks occur quite frequently. Hence, we cannot reject $H I$ and conclude that a stable long-run relationship among the variables does not exist.

An important question is whether some of these breakpoints are related to major economic or political events. The first two breakpoints located in July of 1977 and

\footnotetext{
25 The results are available on request.
} 
September 1981 cannot be matched up with one specific incident, although the second date refers to the so-called pseudo-monetarism policy of the Federal Reserve of 1979 and 1982 (Timberlake 1993). The instability during the mid-1980s coincides with the end of the rise of the US dollar. During that time it had been officially stated by the authorities that the strong dollar was no longer wanted, as it harmed the US economy (Destler and Henning 1989).

The next breakpoint, located around October 1988 (row 4, Table 2), might be traced back to a specific monetary policy stance. In 1988, the monetary policy stance on both sides of the Atlantic, i.e. that of the US Fed and the Bundesbank, became more restrictive. Besides the usual monetary policy suspects, the election of George Bush Senior and the G-7 summit in Berlin ${ }^{26}$ offer further and quite popular explanations.

Whereas any meaningful interpretation of the breakpoint of 1991 appears to be quite arbitrary, the assessment of the following instability in 1993 appears to be more straightforward. It is usually attributed to the crisis of the European Monetary System. Significant changes in the US and German monetary policies at this time are also taken into account by many scholars.

After a relatively stable period up to the end of the 1990s, the next instability emerges shortly after the start of EMU. The last break in 2004 coincides exactly with an event which saw the short-term interest rates of the euro area declining below the level of US interest rates. Of course, as far as the dating of breakpoints and their economic interpretation are concerned, we prefer to follow quite standard appraisals. Nor should one forget that many other important developments are not reflected by breakpoints. Furthermore, it remains a difficult task to identify the exact trigger which caused the observed instabilities. Nevertheless, it seems that policy announcements seem to play an important role in determining the breakpoints detected by the Bai and Perron procedure. We leave a closer examination of the identified breakpoints to future research.

\subsubsection{Testing for cointegration between the exchange rate and fundamentals}

Our second hypothesis is related to the question of whether the estimated relationship can actually be interpreted as a cointegration relationship. The corresponding hypothesis runs as follows:

H2 The estimated relationship can be interpreted as a cointegrating relationship between exchange rates and fundamentals.

$H 2$ can be investigated by applying unit root tests to the error term. If we are able to reject the null of non-stationarity according to the unit root test results, we feel legitimized to conclude that $H 2$ holds. As a first step, we estimate Eq. 23 by FMOLS, using the obtained break dates displayed in Table 2. The corresponding empirical results are presented in Table 3 . They will be analyzed in more detail in Sect. 4.3.3.

\footnotetext{
${ }^{26}$ In contrast to previous meetings, the participants of the Berlin meeting did not publically claim that fluctuations in the dollar were unwanted.
} 


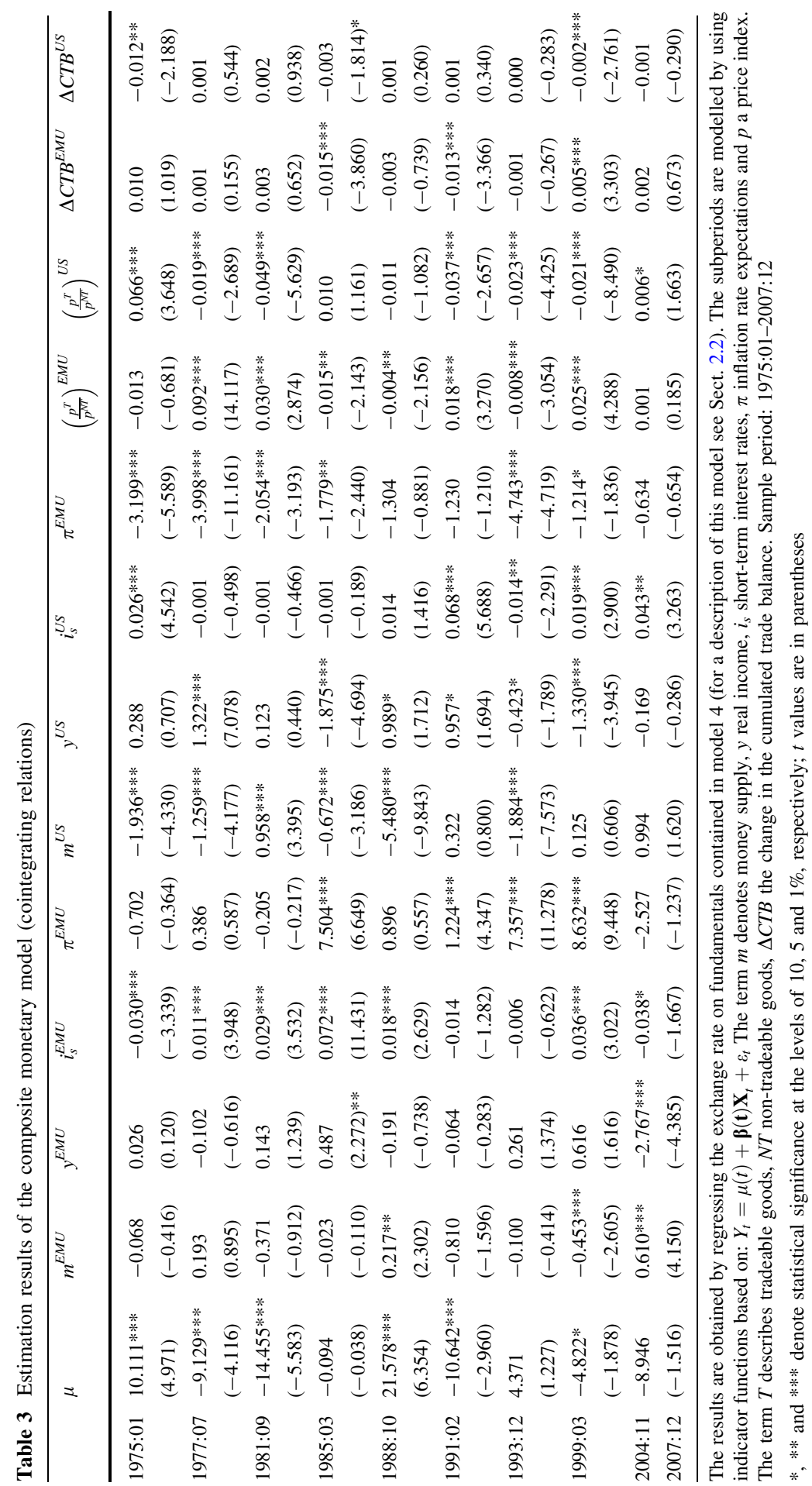


Table 4 Unit root tests for the error terms

\begin{tabular}{|c|c|c|c|c|c|c|}
\hline \multirow{2}{*}{$\begin{array}{l}\text { PP } \\
\text { Test statistic }\end{array}$} & \multicolumn{2}{|c|}{ Critical values } & \multicolumn{2}{|c|}{ DF-GLS } & \multicolumn{2}{|c|}{ Critical values } \\
\hline & $1 \%$ level & $5 \%$ level & Lags & Test statistic & $1 \%$ level & $5 \%$ level \\
\hline$-15.71 * * *$ & -5.86 & -4.31 & 2 & $-15.859 * * *$ & -5.52 & -4.23 \\
\hline
\end{tabular}

Both the PP test and the DF-GLS test assume that the series contains a unit root under the null. To obtain the relevant critical values we ran a simulation with a sample size of 10,000 for each model. Sample period: 1975:01-2007:12

*** denotes statistical significance at the level of $1 \%$

In order to check whether the relationship obtained from the FM-OLS estimation can truly be interpreted as a cointegration relationship, we apply unit root tests to the resulting error series, strictly following the idea of residual-based cointegration tests. In doing so, we have to apply critical values which take account of the number of estimated coefficients. Because of the huge number of coefficients used in our estimation we should not rely on the standard critical values provided by the literature. For this reason, we separately run a Monte-Carlo simulation with 10,000 repetitions in order to obtain critical values for our model. ${ }^{27}$ According to the results of the DF-GLS and the PP test reported in Table 4 the error term resulting from our step-wise relationship should be considered as stationary. This in turn conveys clear evidence in favour of a long-run cointegrating relationship between the exchange rate and its fundamentals. Hence, we accept our second hypothesis $H 2$.

\subsubsection{Estimation and interpretation of the long-run relationship}

We proceed by putting the results of the FM-OLS estimation under closer scrutiny. The validation of $H 2$ raises the question whether the exchange rate is linked to fundamental factors during each regime. In order to check this, our third hypothesis runs as follows:

H3 There is no regime in the step-wise long-run relationship in which no fundamental factor enters.

One option to assess the validity of hypothesis $H 3$ is to apply Wald tests to our composite model which we estimate by means of FM-OLS. Under the null hypothesis, all coefficients except the constant terms are restricted to zero. Any empirical rejection of this null hypothesis confirms our hypothesis $H 3$. The results concerning these restrictions can be found in column (1) of Table 5.

This hypothesis is clearly rejected at the $1 \%$ level in all cases, implying that at least one coefficient except the intercept term is different from zero. Hence, we feel

\footnotetext{
27 To be more precise, we construct the data generating process for each variable. Each process is constructed as an independent random walk. In addition, we take account for the breaks obtained by each model. Consequently, the null hypothesis is no cointegration, meaning that we obtain a series for the error term that contains a unit root for each model. The critical values can then be drawn from the realized distribution. However, this methodology cannot be applied to the KPSS test which assumes stationarity under the null. In this case, we would need to know the exact specification of the cointegration relationship under the consideration of our breaks to obtain relevant critical values. We therefore decided to leave out the KPSS test and to rely on the DF-GLS and the PP test.
} 


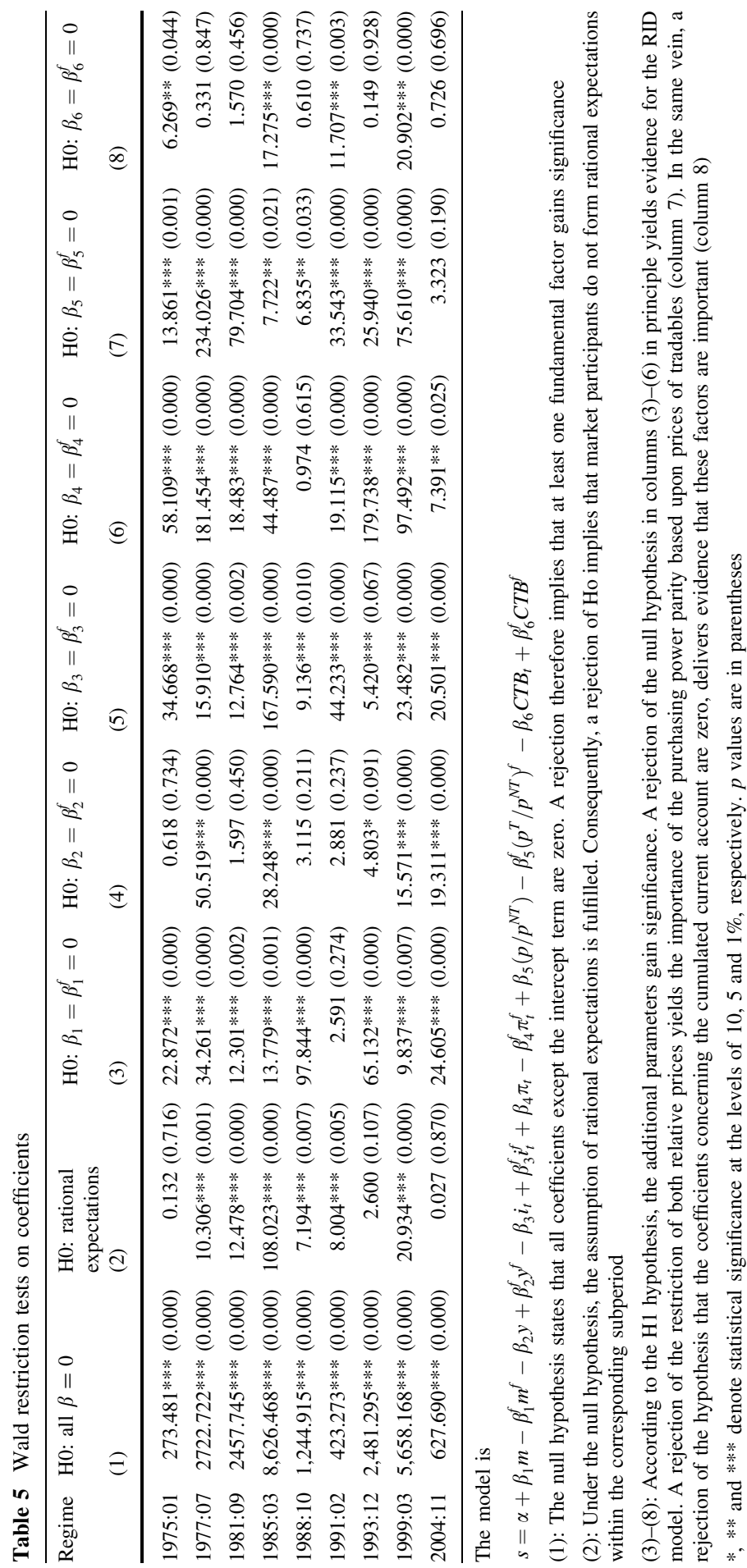


legitimized to argue that $\mathrm{H3}$ is corroborated, i.e. that at least one fundamental variable is significant with respect to the exchange rate (as a non-rejection would have implied that no fundamentals matter).

Since we accept $H 3$, the next interesting question is whether some of the regimes are perseverative. As already mentioned in Sect. 1, many studies assume that the relationship between exchange rate and fundamentals can be described by models that distinguish between two perseverative regimes. Hence, we move on to our fourth hypothesis:

\section{H4 There is no perseverative regime in the step-wise long-run relationship.}

As a prerequisite of our test of this hypothesis, we implement restrictions aimed at achieving the structure of the theoretical models outlined in Sect. 2.1 for our estimated composite model. In order to test the validity of the RID model, we restrict step by step the coefficients of money supply, income, inflation and both interest rates to zero. The results can be seen in columns (3)-(6) of Table 5. A rejection of the null hypothesis in principle yields evidence in favour of the RID model. As a next step, we restrict only the two relative prices to zero. A rejection of this hypothesis yields the importance of the purchasing power parity based upon prices of tradables. In the same vein, a rejection of the hypothesis that the coefficients of the cumulated current account are zero delivers evidence that these factors are important.

Our strategy for checking the validity of hypothesis $H 4$ starts from these Wald tests. First, we assess empirically whether there are similar combinations concerning the rejection or non-rejection of the null hypotheses regarding the subsequent Wald tests. If there is no similar combination, $H 4$ is already confirmed; if there are similar combinations we additionally inspect our estimated regimes. $H 4$ can then not be rejected if at least one coefficient is significant in one regime, while this is not the case in the other regime(s). What is more, the models can also only be confirmed if the signs of the estimated coefficients are in line with underlying theory. Thus, we have to look at the sign of the estimated coefficient in the corresponding regime in order to verify general consistency with a model.

The results of the different tests presented in Table 5 clearly suggest that the variables included in the RID are significant and, hence, important. Altogether, we find similar results only for the periods starting from 1985 to 1999 , as the null hypothesis is always rejected in both cases. However, comparing the results of these periods with respect to the estimation results of Table 4, many coefficients are significant in one period but not in another. Thus, the suspected linkage between exchange rates and fundamentals differs in each period. Hence, we can confirm $H 4$.

As a next step, we take the results for the different regimes displayed in Table 3 under closer scrutiny, with regard to the consistency of the different model configurations. An interesting result is that in cases of significance both inflation rates always enter the equation with the correct sign. The same is true in most cases for the estimated coefficients of the US money supply and the US tradable to nontradable price ratio, while in many cases the corresponding German and European coefficient signs are not consistent with theory. Overall, our results are broadly consistent with the real interest rate model (Eq. 4) in the first two subperiods, after 
our period of observation has started (row 1 and 2 of Table 3). From this point of view, our empirical results clearly corroborate the findings in the literature concerning the early period after the breakdown of Bretton Woods I. ${ }^{28}$ The significant coefficients for the period from 1991 to 1993 always enter with the correct signs. Furthermore, the tradable-non-tradable price ratio of the United States is the only significant variable that enters with the wrong sign during the last period. In all other cases the pattern of the estimation results is less clear, as some coefficients enter with signs that are not consistent with standard theory while others do reflect theoretical considerations. However, some fundamentals gain in significance in each period. Thus, we can conclude that the relationship between exchange rates and fundamentals over a period of at least one and a half years is stable (otherwise the Bai-Perron test would have estimated more breaks, as our configuration allows for breaks every 12 months). However, it is not possible to confirm one specific model over the whole period, as the signs and the significance levels of the coefficients differ across the periods. Although fundamentals seem to matter, the standard exchange rate models considered in this paper do not provide a complete explanation of how they do. Another interesting finding is that the US variables seem to enter more often with correct signs compared to the German and European coefficients.

In the following stage, we test whether a symmetry restriction on short-run interest rates is empirically valid. As mentioned in Sect. 2.1, Goldberg (2000) has shown that rejecting this restriction implies a rejection of the rational expectations hypothesis and basically gives evidence in favor of the imperfect knowledge approach. Accordingly, our fifth hypothesis is formulated as:

\section{H5 The symmetry restriction on short-run interest rates is rejected in each period.}

When testing this hypothesis, we restrict the coefficients of the interest rates to be equal to each other. The results are presented in column (2) of Table 5. A rejection of this restriction would contradict the assumption of rational expectations. In our case, the rational expectation hypothesis has to be rejected in six out of nine cases. Only the first and the last period provide clear evidence in favour of symmetry, while the subsample ranging from 1993 until 1999 might be interpreted as a borderline case. This result is of interest in our context, as the significant coefficients during the first and last subperiods mostly enter with the correct sign which supports the possible coincidence of rational expectations.

\subsubsection{Analysis of the adjustment mechanism}

A further important question is whether the error-correction mechanism which should be stationary according to our reasoning in Sect. 4.3.2, is also subject to structural change. Consequently, we formulate our sixth hypothesis, which addresses the adjustment process of the exchange rate towards its long-run relationship in combination with the stability of the adjustment process:

\footnotetext{
$\overline{28}$ For an early overview see, for example, Isard (1987).
} 
Table 6 Dating of breakpoints in the error-correction model

\begin{tabular}{lc}
\hline Year & Month \\
\hline 1980 & 07 \\
1985 & 03 \\
1987 & 02 \\
No. of breaks: 3 & \\
\hline
\end{tabular}

The reported breakpoints are obtained by applying the Bai and Perron $(1998,2003)$ methodology to the regression $\Delta s_{t}=\zeta(t)+\alpha(t) e c t_{t-1}+\varepsilon_{t}$ for the error correction estimation of the composite model described in Sect. 2. Sample period: 1975:01-2007:12

H6 The adjustment process towards the long-run relationship is not stable, but the exchange rate always adjusts to disequilibria.

To tackle this question we apply the Bai and Perron test once again. In order to test the first part of $H 6$, our strategy is nearly the same as in the case of $H 1$. The only difference is that the Bai-Perron test is applied to the error correction representation as given in Eq. 27, instead of applying it directly to the original FM-OLS estimation as before.

The results, which we summarize in Table 6, show that we are able to identify three breakpoints for our model. However, this result is just the first step towards an assessment of hypothesis $H 6$.

H6 can again be confirmed by using Wald tests. Under the null hypothesis, the adjustment coefficients are restricted to zero. A rejection therefore corresponds with the view that the exchange rate is not weakly exogenous and always adjusts to disequilibria obtained from the FM-OLS regression. If there is an adjustment throughout towards the long-run equilibrium we additionally have to test for differences in the coefficients' magnitude in each regime, in order to clarify whether the adjustment speed is different within the identified regimes. These tests are necessary because the identified breaks can be due to a change in the constant and not to the adjustment coefficient itself. Again, we are using Wald tests assuming that coefficient equality is fulfilled under the null hypothesis.

A regression of the change in the exchange rate on the error term shows that the deviation of the exchange rate from its equilibrium as determined by the cointegrating relation is always significant and, as expected from theory, enters with a negative coefficient. The corresponding results are presented in Table 7.

However, the significance of the deviation in the first period is a borderline case. The tests for weak exogeneity of the exchange rate can be found in the last line of Table 7. The corresponding results are in line with the evidence based on the $t$-statistics: Weak exogeneity can broadly be rejected. Only in the first period is the adjustment of the exchange rate to deviations from the long-run equilibrium rather weak. We present our tests of the equality of the adjustment coefficients in Table 8 .

From these results it follows that the equality restrictions can broadly be rejected in four out of six cases. The similarity of adjustment speed in the first and the fourth regime is borderline in terms of significance. Furthermore, the adjustment coefficients in the second and third regimes cannot be rejected to be similar in 
Table 7 Error-correction estimations

\begin{tabular}{lllll}
\hline Period & $1975: 01$ & $1980: 07$ & $1985: 03$ & \multicolumn{2}{l}{$1987: 02$} \\
& 1 & 2 & 3 & 4 \\
\hline$\zeta(t)$ & $-0.004[-1.584]$ & $0.016^{* * *}[3.507]$ & $-0.022^{* * *}[-4.782]$ & $0.003[0.936]$ \\
$\alpha(t)$ & $-0.191 *[-1.661]$ & $-0.707 * *[-4.760]$ & $-0.642 * * *[-8.034]$ & $-0.389 * * *[-5.876]$ \\
$H 0: \alpha(t)=0$ & $2.760 *(0.097)$ & $22.656^{* * *}(0.000)$ & $64.539 * *(0.000)$ & $34.525 * * *(0.000)$ \\
\hline
\end{tabular}

The results are obtained by regressing the exchange rate in first differences on the one period lagged error term. The subperiods are modelled by using indicator functions based on: $\Delta s_{t}=\zeta(t)+\alpha(t) e c t_{t-1}+\varepsilon_{t}$ The last column displays results of tests for weak exogeneity of the exchange rate. Sample period: 1975:01-2007:12

$*$, ** and *** denote statistical significance at the levels of 10,5 and $1 \%$, respectively; $t$ values are in square brackets and $p$ values in parentheses

Table 8 Wald tests of equality of the adjustment coefficients

\begin{tabular}{llllll}
\hline$H 0: \alpha_{1}=\alpha_{2}$ & $H 0: \alpha_{1}=\alpha_{3}$ & $H 0: \alpha_{1}=\alpha_{4}$ & $H 0: \alpha_{2}=\alpha_{3}$ & $H 0: \alpha_{2}=\alpha_{4}$ & $H 0: \alpha_{3}=\alpha_{4}$ \\
\hline $7.512 * * *(0.006)$ & $10.317 * * *(0.001)$ & $2.213(0.137)$ & $0.149(0.699)$ & $3.822 *(0.051)$ & $5.914 * *(0.015)$
\end{tabular}

Under the null hypothesis the adjustment coefficients are restricted to be equal. A rejection conveys evidence in favour of different adjustment speeds

$*$, ** and $* * *$ denote statistical significance at the levels of 10,5 and $1 \%$, respectively. $p$ values are in parentheses

magnitude. As can be seen from all estimated coefficients, the constant term is mainly responsible for the breaks found up to the end of the 1980 s because the regimes coincide with long swings in the exchange rates. This implies that a change in the intercept term corresponds to a change in the longer-run growth rate of the nominal exchange rate.

Hence, we conclude that structural breaks in the cointegration coefficients are more frequent than in the adjustment coefficients. However, H6 cannot be rejected, which means that there is always a dynamic in which the exchange rate reacts to fundamentals. Again, the location of the breaks in some cases can be associated with economic developments. The explanations offered for the breaks in the cointegrating coefficients for 1985 can again be applied. In addition, the last breakpoint occurs in 1987, with the Louvre accord as a possible cause.

\section{Conclusions}

In this paper, we have empirically examined the long-run relationship between the US dollar/euro exchange rate and fundamentals under special consideration of structural breaks in the underlying coefficients. We have shown that fundamentals are important in each subperiod but that their impact differs significantly depending on various regimes. With respect to this issue we draw some major conclusions.

One result we come up with is that there are no perseverative regimes, which implies that either the empirical realisations of the estimated coefficient for the same 
fundamentals or their significance values differ. Insofar as efficient forex market intervention presupposes the exact knowledge of the dollar/euro equilibrium exchange rate, this makes exchange rate targeting a technically demanding exercise because it has to deal with a moving target. Moreover, our results contradict the view that fundamentals only matter during single periods, while having no explanatory content within other regimes. Goldberg and Frydman (2001) offer a possible explanation of our findings. In their view, market participants change the theories with respect to the fundamentals they use to forecast exchange rate movements. Those changes in turn influence the paths of the exchange rate. They might in some cases also be explained by the specific economic events we address to illustrate our findings in Chapter 4.

In technical terms, we were able to establish the existence of cointegrating relations by testing the respective error terms for stationarity. Moreover, the dollar/ euro exchange rate significantly adjusts to deviations from the step-wise linear relationships in all cases with the adjustment speed also differing.

Altogether, modelling the dollar/euro exchange rates in a linear fashion appears to be inadequate in many instances. Thus, we feel legitimized to claim that the poor empirical record of some standard monetary exchange rate models can be attributed to, among other factors, the assumption of regression coefficients which do not change over time. Another result is that, in some instances, specific economic developments can well be identified and addressed to explain the date of the breaks. The same is true concerning the specific character of estimated relationships between the reported fundamentals and the exchange rate for the different periods.

The topic addressed by us surely needs further attention. While our focus has been on the exchange rate, an analogous study could also be conducted for the extensive evidence of coefficient instability established in the case of other (forward-looking) macroeconomic and financial data. Separate from the interesting question of what accounts for the time-varying relationship between exchange rates and fundamentals, there is also the open issue what its policy implications are (Bacchetta and van Wincoop 2009). We leave the interesting task of corroborating our results for other currency pairs or other model configurations to further research.

Acknowledgments We are grateful for valuable comments from the participants of the Annual Meeting of the German Economic Association (Verein für Socialpolitik), September 8-11, 2009, Magdeburg, of the XII. Applied Economics Meeting Conference, held from June 4-6, 2009, Madrid, and of the 12th Workshop on International Economic Relations, March 12-14, 2009, Goettingen. We gratefully acknowledge from helpful comments from an anonymous referee.

Open Access This article is distributed under the terms of the Creative Commons Attribution Noncommercial License which permits any noncommercial use, distribution, and reproduction in any medium, provided the original author(s) and source are credited.

\section{References}

Abhyankar, A., Sarno, L., \& Valente, G. (2005). Exchange rates and fundamentals: Evidence on the economic value of predictability. Journal of International Economics, 66(2), 325-348.

Andrews, D. W. K., \& Monahan, J. C. (1992). An Improved heteroskedasticity and autocorrelation consistent covariance matrix estimator. Econometrica, 60(4), 953-966. 
Andrews, D. W. K., \& Ploberger, W. (1996). Testing for serial correlation against an ARMA(1, 1,) process. Journal of the American Statistical Association, 91(435), 1331-1342.

Bacchetta, P., \& van Wincoop, E. (2004). A scapegoat model of exchange-rate fluctuations. The American Economic Review, 94(2), 114-118.

Bacchetta, P., \& van Wincoop, E. (2009). On the unstable relationship between exchange rates and macroeconomic fundamentals, (NBER Working Paper 15008), National Bureau of Economic Research, Cambridge, MA.

Bai, J., \& Perron, P. (1998). Estimating and testing linear models with multiple structural changes. Econometrica, 66(1), 47-78.

Bai, J., \& Perron, P. (2003). Computation and analysis of multiple structural change models. Journal of Applied Econometrics, 18(1), 1-22.

Balassa, B. (1964). The purchasing-power parity doctrine: A reappraisal. Journal of Political Economy, 72(6), 584-596.

Belke, A. (2000). Partisan political business cycles in the German labour market? Empirical tests in the light of the Lucas-critique. Public Choice, 104(3-4), 225-283.

Berkowitz, J., \& Giorgianni, L. (2001). Long-horizon exchange rate predictability? Review of Economics and Statistics, 83(1), 81-91.

Branson, W. H. (1977). Asset markets and relative prices in exchange rate determination. Sozialwissenschaftliche Annalen, 1(20), 69-89.

Caporale, G. M., \& Pittis, N. (1999). Efficient estimation of cointegration vectors and testing for causality in vector autoregressions. Journal of economic surveys, 13(1), 1-35.

Cappuccio, N., \& Lubian, D. (2001). Estimation and Inference on long-run equilibria: A simulation study. Econometric Reviews, 20(1), 61-84.

Carrion-i-Silvestre, J. L., \& Sanó, A. (2006). Testing the null of cointegration with structural breaks. Oxford Bulletin of Economics and Statistics, 68(5), 623-646.

Cheung, Y.-W., \& Chinn, M. D. (2001). Currency traders and exchange rate dynamics: A survey of the US market. Journal of International Money and Finance, 20(4), 439-471.

Cheung, Y.-W., Chinn, M. D., \& Pascual, A. G. (2005). Empirical exchange rate models of the nineties: Are any fit to survive? Journal of International Money and Finance, 24(7), 1150-1175.

Chinn, M. D., \& Meese, R. A. (1995). Banking on currency forecasts: How predictable is change in money? Journal of International Economics, 38(1-2), 161-178.

De Grauwe, P., \& Vansteenkiste, I. (2007). Exchange rates and fundamentals: A non-linear relationship? International Journal of Finance and Economics, 12(1), 37-54.

Destler, I. M., \& Henning, C. R. (1989). Dollar politics: Exchange rate policymaking in the United States. Washington, DC: Institute for International Economics.

Dornbusch, R. (1976a). Expectations and exchange rate dynamics. The Journal of Political Economy, 84(6), 1161-1176.

Dornbusch, R. (1976b). The theory of flexible exchange rate regimes and macroeconomic policy. Scandinavian Journal of Economics, 78(2), 255-275.

Elliot, G., Rothenberg, T. J., \& Stock, J. H. (1996). Efficient tests for an autoregressive unit root. Econometrica, 64(4), 813-836.

Engle, R. F., \& Granger, C. (1987). Co-integration and error correction: Representation, estimation, and testing. Econometrica, 55(2), 251-275.

Engle, R. F., \& Yoo, S. (1991). Cointegrated economic time series: An overview with new results. In R. F. Engle \& C. W. J. Granger (Eds.), Long run economic relationships-Readings in cointegration (pp. 237-266). Oxford: Oxford University Press.

Frankel, J. A. (1979). On the Mark: A theory of floating exchange rates based on real interest differentials. American Economic Review, 69(4), 610-622.

Frankel, J. A. (1983). Monetary and portfolio-balance models of exchange rate determination. In J. S. Bhandari \& B. H. Putnam (Eds.), Economic interdependence and flexible exchange rates (pp. 84-115). Cambridge: MIT Press.

Fratianni, M., \& von Hagen, J. (1990). German dominance in the EMS: The empirical evidence. Open Economic Review, 1(1), 67-87.

Frenkel, J. A. (1976). A Monetary approach to the exchange rate: Doctrinal aspects and empirical evidence. Scandinavian Journal of Economics, 78(2), 200-224.

Frömmel, M., MacDonald, R., \& Menkhoff, L. (2005a). Do fundamentals matter for the D-mark/eurodollar? A regime switching approach. Global Finance Journal, 15(3), 321-335. 
Frömmel, M., MacDonald, R., \& Menkhoff, L. (2005b). Markov switching regimes in a monetary exchange rate model. Economic Modelling, 22(3), 485-502.

Frydman, R., Goldberg, M., Johansen, S., \& Juselius, K. (2010). Testing hypotheses in an I(2) model with applications to the persistent long swings in the Dmk/\$ rate. Journal of Econometrics, (forthcoming).

Gehrig, T., \& Menkhoff, L. (2006). Extended evidence on the use of technical analysis in foreign exchange. International Journal of Finance and Economics, 11(4), 327-338.

Goldberg, M. D. (2000). On empirical exchange rate models: What does a rejection of the symmetry restriction on short-run interest rates mean? Journal of International Money and Finance, 19(5), 673-688.

Goldberg, M. D., \& Frydman, R. (1996a). Imperfect knowledge and behaviour in the foreign exchange market. Economic Journal, 106(437), 869-893.

Goldberg, M. D., \& Frydman, R. (1996b). Empirical exchange rate models and shifts in the co-integrating vector. Structural Change in Economic Dynamics, 7(1), 55-78.

Goldberg, M. D., \& Frydman, R. (2001). Macroeconomic fundamentals and the DM/\$ exchange rate: Temporal instability and the monetary model. International Journal of Finance and Economics, 6(4), 421-435.

Goldberg, M. D., \& Frydman, R. (2007). Imperfect knowledge economics: Exchange rates and risk. Princeton: Princeton University Press.

Gregory, A. W., \& Hansen, B. E. (1996). Residual-based tests for cointegration in models with regime shifts. Journal of Econometrics, 70(1), 99-126.

Groen, J. J. J. (1999). Long horizon predictability of exchange rates: Is it for real? Empirical Economics, 24(3), 451-469.

Hansen, P. R. (2003). Structural changes in the cointegrated vector autoregressive model. Journal of Econometrics, 114(2), 261-295.

Hansen, H., \& Johansen, S. (1999). Some tests for parameter constancy in cointegrated VAR-models. Econometrics Journal, 2(2), 306-333.

Hargreaves, C. (1994). A review of estimating cointegrating relationships. In C. Hargreaves (Ed.), Nonstationary time series analysis and cointegration (pp. 87-131). Oxford: Oxford University Press.

Harrod, R. (1939). International economics. Cambridge: Cambridge University Press.

Haynes, S. E., \& Stone, J. A. (1981). On the Mark: Comment. American Economic Review, 71(5), 1060-1067.

Hooper, P., \& Morton, J. (1982). Fluctuations in the dollar: A model of nominal and real exchange rate determination. Journal of International Money and Finance, 1(1), 39-56.

Isard, P. (1987). Lessons from empirical models of exchange rates. IMF Staff Papers, 34(1), 3-28.

Johansen, S. (1988). Statistical analysis of cointegration vectors. Journal of Economic Dynamics and Control, 12(2-3), 231-254.

Juselius, K. (2006). The cointegrated VAR approach: Methodology and applications. Oxford: Oxford University Press.

Kejriwal, M., \& Perron, P. (2008). Testing for multiple structural changes in cointegrated regression models. (Working paper no. 1216). Boston University.

Kilian, L. (1999). Exchange rate and monetary fundamentals: What do we learn from long-horizon regressions? Journal of Applied Econometrics, 14(5), 491-510.

Kilian, L., \& Taylor, M. P. (2003). Why is it so difficult to beat the random walk forecast of exchange rates. Journal of International Economics, 60(1), 85-107.

Kouri, P. J. K. (1976). The exchange rate and the balance of payments in the short run and in the long run: A monetary approach. Scandinavian Journal of Economics, 78(2), 280-304.

Kwiatkowski, D., Phillips, P. C. B., Schmidt, P., \& Shin, Y. (1992). Testing the null hypothesis of stationarity against the alternative of a unit root. Journal of Econometrics, 54(1-3), 159-178.

Leventakis, J. A. (1987). Exchange rate models: Do they work? Weltwirtschaftliches Archiv/Review of World Economics, 123(2), 1-12.

MacDonald, R., \& Taylor, M. P. (1993). The monetary approach to the exchange rate: Rational expectations, long-run equilibrium and forecasting. (IMF working paper, WP/92/34), International Monetary Fund, Washington, D.C.

MacDonald, R., \& Taylor, M. P. (1994). The monetary model of the exchange rate: Long-run relationships, short-run dynamics and how to beat the random walk. Journal of International Money and Finance, 13(3), 276-290. 
MacKinnon, J. G. (1991). Critical values for cointegration tests in long-run economic relationships. Readings in cointegration (pp. 267-276). New York: Oxford University Press.

Mark, N. C. (1995). Exchange rates and fundamentals: Evidence on long-horizon predictability. American Economic Review, 85(1), 201-218.

Meese, R. A., \& Rogoff, K. (1983). Empirical exchange rate models of the seventies. Journal of International Economics, 14(1-2), 3-24.

Meese, R. A., \& Rogoff, K. (1988). Was it real? The exchange rate-interest differential relation over the modern floating-rate period. Journal of Finance, 43(4), 933-948.

Mussa, M. (1976). The exchange rate, the balance of payments and monetary and fiscal policy under a regime of controlled floating. Scandinavian Journal of Economics, 78(2), 229-248.

Newey, W. K., \& West, K. D. (1987). Heteroskedasticity and autocorrelation consistent covariance matrix estimation. Econometrica, 55(3), 703-708.

Ng, S., \& Perron, P. (2001). Lag length selection and the construction of unit root tests with good size and power. Econometrica, 69(6), 1519-1554.

Nyblom, J. (1989). Testing for the constancy of parameters over time. Journal of the American Statistical Association, 84(405), 223-230.

Obstfeld, M., \& Rogoff, K. (1995). Exchange rate dynamics redux. Journal of Political Economy, 103(3), $624-660$.

Perron, P., \& Yamamoto. Y. (2008). Estimating and testing multiple structural changes in models with endogenous regressors, (working paper 2008-017), Boston University.

Phillips, P. C. B. (1991). Optimal inference in cointegrated systems. Econometrica, 59(2), 283-306.

Phillips, P. C. B. (1995). Fully modified least squares and vector autoregression. Econometrica, 63(5), 1023-1078.

Phillips, P. C. B., \& Hansen, B. E. (1990). Statistical inference in instrumental variables regression with I(1) processes. Review of Economic Studies, 57(1), 99-125.

Phillips, P. C. B., \& Loretan, M. (1991). Estimating long-run economic equilibria. Review of Economic Studies, 58(3), 407-436.

Rogoff, K. (2009). Exchange rates in the modern floating era: What do we really know? Review of World Economics/Weltwirtschaftliches Archiv, 145(1), 1-12.

Rossi, B. (2006). Are exchange rates really random walks? Some evidence robust to parameter instability. Macroeconomic Dynamics, 10(1), 20-38.

Samuelson, P. (1964). Theoretical notes on trade problem. Reviews of Economics and Statistics, 46(2), $145-154$.

Sarno, L., \& Valente, G. (2009). Exchange rates and fundamentals: Footloose or evolving relationship? Journal of the European Economic Association, 7(4), 786-830.

Sarno, L., Valente, G., \& Wohar, M. E. (2004). Monetary fundamentals and exchange rate dynamics under different nominal regimes. Economic Inquiry, 42(2), 179-193.

Schinasi, G. J., \& Swamy, P. A. V. B. (1989). The out-of-sample forecasting performance of exchange rate models when coefficients are allowed to change. Journal of International Money and Finance, $8(3), 375-390$.

Schwert, G. W. (1989). Tests for unit roots: A Monte Carlo investigation. Journal of Business and Economics Statistics, 7(2), 147-159.

Siklos, P. L., \& Granger, C. W. J. (1997). Regime-sensitive cointegration with an application to interestrate parity. Macroeconomic Dynamics, 1(3), 640-657.

Stock, J. H., \& Watson, M. W. (1988). Testing for common trends. Journal of the American Statistical Association, 83(404), 1097-1107.

Stock, J. H., \& Watson, M. W. (1996). Evidence in structural instability in macroeconomic time series relations. Journal of Business and Economic Statistics, 14(1), 11-30.

Taylor, M. P., \& Peel, D. A. (2000). Nonlinear adjustment, long-run equilibrium and exchange rate fundamentals. Journal of International Money and Finance, 19(1), 33-53.

Taylor, M. P., Peel, D. A., \& Sarno, L. (2001). Nonlinear mean-reversion in real exchange rates: Toward a solution to the purchasing power parity puzzles. International Economic Review, 42(4), 1015-1042.

Timberlake, R. H. (1993). Monetary policy in the United States-An intellectual and institutional history. Chicago: University Of Chicago Press.

Wilson, C. A. (1979). Anticipated shocks and the exchange rate. The Journal of Political Economy, 87(3), 639-647. 
Wolff, C. C. P. (1987). Time-varying parameters and the out-of-sample forecasting performance of structural exchange rate models. Journal of Business and Economic Statistics, 5(1), 87-97.

Wu, J., \& Hu, Y. (2009). New evidence on nominal exchange rate predictability. Journal of International Money and Finance, 28(6), 1045-1063.

Zeileis, A., Kleiber, C., Krämer, W., \& Hornik, K. (2003). Testing and dating of structural changes in practice. Technical Report, 39, Dortmund.

Zumaquero, A., \& Urrea, R. (2002). Purchasing power parity: Error-correction models and structural breaks. Open Economies Review, 13(1), 5-26. 